\begin{tabular}{|l|l|}
\hline Postprint Version & 1.0 \\
\hline Journal website & http://dx.doi.org/10.1016/j.pec.2010.07.032 \\
\hline Pubmed link & http://www.ncbi.nlm.nih.gov/pubmed/20817453 \\
\hline DOI & $10.1016 /$ j.pec.2010.07.032 \\
\hline
\end{tabular}

This is a NIVEL certified Post Print, more info at http://www.nivel.eu

\title{
Preferences and experiences of chronically ill and disabled patients regarding shared decision-making: Does the type of care to be decided upon matter?
}

\author{
Atie Van den Brink-Muinen, ${ }^{\text {A }}$, Peter Spreeuwenberg, ${ }^{\text {A }}$ AND Mieke RiJKen ${ }^{1, \text { A }}$
}

${ }^{a}$ NIVEL (Netherlands Institute for Health Services Research), The Netherlands

\begin{abstract}
Objective: (1) To describe the importance chronically ill and disabled patients attach to involvement in decision-making when various care types are considered, and (2) to analyse the degree to which these patients are involved in shared decision-making (SDM) regarding these care types, and whether their involvement reflects the importance they attach to SDM.

Methods: The study sample consisted of 812 chronically ill and disabled patients who experienced a situation of decision-making during the last year. Data were collected by a selfreport survey in 2006 and were analysed by multilevel linear regression analyses.

Results: Participants attached most importance to SDM when occupational healthcare issues were at stake, but perceived their actual involvement in these decisions as relatively low. Patients dealing with decision-making regarding medical care or home care experienced higher levels of involvement. The importance attached to SDM corresponds moderately with the actual role patients experience in the decision-making process.

Conclusion: The type of care to decide upon impacts on the importance patients attach to SDM as well as on their actual involvement in decision-making.

Practice implications: We suggest healthcare practitioners to pay attention to the preferred level of patient involvement each time a new care issue has to be decided upon.
\end{abstract}

\section{INTRODUCTION}

\subsection{BACKGROUND}

In the past decades a paradigm shift has taken place in western societies with respect to the relationship between care providers and patients or clients. There has been a move from an authoritarian to a more egalitarian (or democratic) relationship [1] and [2], which may have influenced the extent to which patients are being involved in decisions regarding their care. Patients are now considered to have the right to know and the right to decide [3].

Shared decision-making (SDM) is an important element in various models of patient centeredness [3], [4], [5], [6] and [7]. A systematic review of the conceptualization of SDM by Makoul and Clayman revealed that there is no standardised definition of the term [4]. To address this, these authors propose an integrative model distinguishing essential and ideal elements (and general qualities) of SDM. Essential elements must 
Brink-Muinen, A. van den, Spreeuwenberg, P., Rijken, M. Preferences and experiences of chronically ill and disabled patients regarding shared decision-making: does the type of care to be decided upon matter? Patient Education and Counseling: 2011, 84(1), 111-117

be present for patients and providers to engage in the process of SDM, whereas ideal elements are not considered necessary, though they may enhance SDM. It is important to note that patient values or preferences are considered an essential element of SDM, in addition to other elements such as presenting the (treatment) options and discussing pros and cons. Patients and providers may have different perspectives of the benefits, risks, and costs of options. These differences can become evident through exploration of the patient's values and preferences as well as the care provider's knowledge and recommendations in the context of the decision in question. In line with this, we define SDM as patient involvement in decision-making about care issues, taking the patient's preferences into account. Or, as Edwards and Elwyn state 'involving patients in decision-making to the extent that they desire' [8].

Several studies in general practice show that the higher importance patients attach to SDM the more often they are involved in SDM. However, although most patients consider SDM important, it is not always realized in accordance with their preferences [2], [9], [10] and [11]. Studies in general medical care settings have shown that SDM increases patients' satisfaction, treatment adherence and understanding, and confidence in the decisions, all of which may contribute to patients' health and well-being [3], [6], [9], [10], [11], [12], [13], [14], [15] and [16]. SDM may be even more important when health problems or disabilities are lasting. People with chronic conditions are often well informed about their health problems and will usually be able and willing to choose between treatment options [17], [18], [19], [20], [21] and [22]. A preference for SDM may also be present when non-medical care issues have to be dealt with. Studying SDM in relation to other types of care (e.g. home care, occupational healthcare, lifestyle issues) is especially important for people with chronic conditions, because of their needs regarding both medical and non-medical types of care in relation to their quality of life.

During the last three decades, many studies have shown that characteristics of patients (and healthcare providers) affect both preferences and actual experiences regarding decision-making. For instance, male and low educated patients have been found to be more likely to leave the decision to the doctor [2], [3] and [20], whereas younger patients more often wish to be involved [23] and [24]. Patients' education level and gender have so far proven to be unrelated to the level of actual involvement in decision-making [2], [9], [20] and [25]. With regard to patients' preferences, Ende et al. [24] found that demographic characteristics and the health status of the patient accounted for only $19 \%$ of the variance in the desire to participate in treatment decisions. This suggests that other factors, besides patient characteristics, need to be considered to better understand patients' preferred roles in decision-making. Regarding patients' experiences, some studies have shown that (general practice) patients who attach more importance to SDM are more often involved in the decision-making process [2] and [10].

Conceptual models of SDM and related concepts [4] and [26] distinguish the following factors that may impact on the decision-making process: patient and provider characteristics (i.e. socio-demographics and the preferred role of both actors in decision-making) and their (different) perceptions on the treatment they have to decide upon (for instance, perceived risks and benefits, uncertainty of outcome). Considering these perceptions as 'state' rather than 'trait' characteristics of patients and care providers, we speculate that the type of care issue to decide upon might also impact on patients' preferences and experiences regarding SDM.

In this study, we wished to explain differences in preferences and experiences regarding SDM beyond the level of the individual characteristics of patients and care providers. We focused on the impact of the type of care issue at stake: does it make a difference for patients' preferences and experiences regarding decision-making, whether the decision to be made concerns a type of medical care or another type of care?

\subsection{Expectations}

We expected both preferences and experiences to depend on the type of care issue at stake. We assumed that the more patients judge their own expertise about a care issue to be as important as the expertise of their care provider, the more they prefer involvement in decision-making and may actually play a significant role in this process. Since patients may perceive their expertise about lifestyle issues to be greater than their medical knowledge, we expected them to attach more value to SDM regarding lifestyle issues than medical issues. Concerning occupational healthcare or home care decisions, we expected more egalitarian roles of patients and care providers in the decision-making process. 
Brink-Muinen, A. van den, Spreeuwenberg, P., Rijken, M. Preferences and experiences of chronically ill and disabled patients regarding shared decision-making: does the type of care to be decided upon matter? Patient Education and Counseling: 2011, 84(1), 111-117

\subsection{Research questions}

1. Is the type of care upon which decisions have to be made related to (a) the importance patients with long-term conditions attach to SDM, and (b) their actual involvement in the decision-making process?

2. To what extent is there a relationship between the importance these patients attach to participation in decision-making regarding various care issues and their actual (experienced) involvement in the decisionmaking process?

\section{METHOD}

\subsection{SAMPLE}

The sample consisted of panel members of the National Panel of people with Chronic illness or Disability (NPCD), a nationwide prospective panel-study in the Netherlands [27]. NPCD provides information about the consequences of chronic illness and disability from patients' perspectives. It supplies core data on perceived health, use of health services and social participation of people with chronic conditions. Each year, patients aged 15 years and older are selected in general practices (random samples) on the basis of a diagnosis of a somatic chronic disease. Additional panel members are selected from national population surveys by a self-report screener on physical disability. Panel members fill in postal questionnaires twice a year and are considered a representative sample of the Dutch population of adult, non-institutionalized (physically) chronically ill and/or disabled persons.

In October 2006, 2423 panel members answered questions relevant to the present study (response 84\%). Of this group, 812 (34\%) reported that a decision had been made during the last year about one or more types of care: medical care $(\mathbf{N}=577)$, home care $(\mathbf{N}=189)$, occupational healthcare $(\mathbf{N}=61)$, or lifestyle $(\mathbf{N}=312)$.

\subsection{Measures}

\subsubsection{Decision-making}

For each of the four care types that were applicable to the respondents, the following questions were asked:

1. What was the most recent decision-making situation you have experienced? (see

Box 1 for pre-structured response options).

Box 1. Categorization of care issues according to type and caregivers involved

\section{[BOX 1]}

2. Which caregiver was (most) involved in this decision-making process? (see

Box 1 for pre-structured response options).

3. Was this caregiver a man or a woman?

4. How important was it for you to be involved in the decision-making process?

5 . To what extent were you involved in the decision?

The importance respondents attached to being involved in the decision-making process was assessed by answering one question $(1=$ not important, 2 = rather important, $3=$ important, $4=$ of the utmost importance). The structure of the question was derived from the Quote-Comm [2], [9] and [10], which surveys preferences regarding matters that include SDM.

Involvement in decision-making was also assessed by one question. In accordance with Makoul and Clayman [4], we formulated five response options: 1 = caregiver decided without consulting the patient, 2 = caregiver decided after consulting the patient, $3=$ patient and caregiver decided together, $4=$ patient decided after consulting the caregiver, and $5=$ patient decided without consulting the caregiver.

\subsubsection{Socio-demographic characteristics}

Included were the patient's gender, age and education level ( $1=$ no/only primary school to $7=$ university $)$ as well as the caregiver's gender.

\subsubsection{Severity of the health condition}

GPs provided information about (1) the extent to which the condition was considered life threatening; (2) the progressiveness of the long-term condition (both rated as $1=$ to a lesser extent to $3=$ to a large extent); 
Brink-Muinen, A. van den, Spreeuwenberg, P., Rijken, M. Preferences and experiences of chronically ill and disabled patients regarding shared decision-making: does the type of care to be decided upon matter? Patient Education and Counseling: 2011, 84(1), 111-117

and (3) the number of chronic diseases diagnosed (dichotomized here: one versus two or more). The severity of disability (4) was assessed by a self-report indicator of long-term physical disability [28] ( 1 = no/mild, 2 = moderate, 3 = severe). Self-rated health (5) was assessed by one item on the SF-36 [29] and [30]: in general, would you say your health is: $1=$ excellent, 2 = very good, $3=$ good, $4=$ fair or $5=$ poor.

\subsection{Data analysis}

Multilevel regression analyses were conducted to adjust for clustering of the four types of care within patients and for clustering of patients within general practices [31]. The first level of analysis was the type of care; the second was that of the patients; the third was the level of general practices (random part). Dependent variables were (1) the importance attached to SDM and (2) the experienced involvement in the decision-making process. The type of care issues, patient characteristics and care providers' gender were included in the fixed part of the model.

Three different multilevel regression analyses were performed. First, we investigated whether the importance attached to SDM depended on the type of care issues involved, besides patient characteristics (see Section 3.3). Next, we examined whether the experienced involvement in decision-making depended on the type of care issue involved, in addition to patient characteristics and caregiver's gender (see Section 3.4). Third, the correlation between the importance attached to SDM and the involvement in the decisionmaking process was assessed (see Section 3.5). In this last analysis we also explored differences in the effects of the various types of care and patient characteristics on the importance attached to SDM and the involvement in decision-making, by means of chi-square tests. To allow comparison of the effects, the scores of the importance and involvement variables were transformed into Z-scores. For all analyses, a significance level of $\mathrm{P}<.05$ (two-sided) was applied.

\section{RESULTS}

\subsection{PATIENT CHARACTERistics}

Respondents who experienced a decision-making situation regarding a medical care issue had a mean age of 60 years; $68 \%$ were female (see Table 1). Half of them suffered from multi-morbidity and two thirds experienced moderate to severe disability. Respondents who experienced a decision-making situation regarding home care were older and mostly female. The majority suffered from multi-morbidity and/or moderate to severe disability; their self-rated health was rather poor. Respondents who experienced decision-making regarding occupational healthcare issues were younger and higher educated. Most of them did not suffer from multi-morbidity and rated their health as relatively good. The group reporting decisions on lifestyle issues comprised a relatively large number of men. Other characteristics in this group were similar to the respondents who experienced decision-making about medical care issues.

\section{[TABLE 1]}

The four groups of respondents were not mutually exclusive, i.e. panel members could have experienced decision-making situations during the last year regarding more than one type of care.

\subsection{Types of care issues and care providers involved}

Medical treatments such as surgery or vaccination (42\%) and medication (32\%) were the most frequently cited types of medical care about which decisions had been made; diagnostics (13\%) and referrals (10\%) less often. Medical specialists (53\%) and GPs (33\%) were most often involved in these situations.

Decisions made about home care mostly concerned domestic care (58\%), and less often nursing or personal care (both 20\%). Two thirds of the care providers involved were home helps (66\%) and one third registered nurses.

The decisions made about occupational healthcare mostly concerned restarting work (41\%), changing to another type of work or reducing workload (20\%), and other/more flexible working hours (12\%). Most care providers involved were occupational physicians (81\%).

Decisions about lifestyle concerned diet and food (54\%) or physical exercise (29\%), and to a lesser extent smoking (6\%) or alcohol use (2\%). GPs (34\%), medical specialists (25\%), allied healthcare professionals other than dieticians (15\%) and dieticians (9\%) were most often involved. 
Brink-Muinen, A. van den, Spreeuwenberg, P., Rijken, M. Preferences and experiences of chronically ill and disabled patients regarding shared decision-making: does the type of care to be decided upon matter? Patient Education and Counseling: 2011, 84(1), 111-117

\subsection{Importance attached to SDM}

The importance attached by the respondents to participate in decision-making regarding medical care and home care issues was about equal (Table 2, fixed part). When occupational healthcare issues were at stake, SDM was found to be more important than when medical issues were concerned. SDM was considered less important with regard to lifestyle issues. The older the patients, the more importance they attached to SDM.

\section{[TABLE 2]}

The variance in the importance attached to SDM was highest when occupational healthcare issues were at stake, and lowest in the case of lifestyle issues (Table 2, random part). This means that the differences between individual patients in the importance they attach to SDM are greatest when the decision involves occupational healthcare issues such as restarting work or altering the type of work or workload. A small, not significant part of the variance at the patient level remains unexplained (after controlling for type of care and patient characteristics already included in the model). At general practice level, no variance was shown, implying that the general practice from which the respondents were recruited did not make any difference with regard to the importance attached to SDM.

\subsection{Involvement in decision-making}

Regarding their actual involvement, respondents felt less involved in decision-making about occupational healthcare and lifestyle issues than about medical care issues (Table 2, fixed part). No differences existed in the (experienced) involvement about medical care and home care issues. Male and older respondents reported greater involvement.

The variance in the involvement in decision-making was highest for medical care issues and lowest for occupational healthcare issues (Table 2, random part). Thus, the differences between the experiences of individual patients with SDM are largest in medical care issues. Some variance between individual patients remains unexplained (after controlling for type of care, care provider's gender and patient characteristics already included in the model). No dispersion was found at the general practice level.

\subsection{Relationship between importance attached to SDM and involvement in decision-making}

There is a significant relationship between the importance patients attach to SDM and their involvement in decision-making. Pearson's correlation coefficient was .41 (model without controlling variables) and .45 (model with controlling variables; Table 2, random part). This indicates that the relationship between preferred and experienced involvement is relatively independent of the socio-demographic and health characteristics of the patients.

The effects of the care issue at stake and controlling variables on the importance attached to SDM and the actual involvement in decision-making were compared by means of chi-square tests (Table 2, fixed part). With respect to occupational healthcare, the results show a discrepancy: patients attach considerable importance to being involved in decision-making, but experience less involvement. Furthermore, gender is hardly related to the importance patients attach to SDM, whereas with respect to the actual involvement female patients experience their role in decision-making to be smaller than males. Lastly, patients who rate their health as worse attach more importance to SDM, but feel less involved in decision-making processes.

\section{DISCUSSION AND CONCLUSION}

\subsection{DISCUSSION}

This is the first study focusing on SDM in both medical and non-medical care settings. During the last decades, SDM has been studied almost entirely within medical care (primary care and hospital care). Studying SDM within the medical encounter has resulted in a substantial amount of knowledge on the impact of individual (patient and provider) characteristics on patients' preferred roles in decision-making and their actual involvement in decision-making processes. Notwithstanding its merits, the narrow focus on SDM in the medical context might be disadvantageous for people suffering from long-term conditions. These people often use other types of care besides medical care, that ask for making sometimes difficult and far-reaching decisions as well. Assuming that patients hold the same preferences for decision-making regardless of the type of care issue, might affect the quality of care, and by this also patients' outcomes such as their quality of life. 
Brink-Muinen, A. van den, Spreeuwenberg, P., Rijken, M. Preferences and experiences of chronically ill and disabled patients regarding shared decision-making: does the type of care to be decided upon matter? Patient Education and Counseling: 2011, 84(1), 111-117

Chronically ill and disabled patients attach more importance to shared decision-making regarding occupational healthcare than medical care issues. Given the importance of their own experience of the work situation, this is not surprising. More surprising for us was that patients do not attach much importance to SDM about lifestyle issues. This may be related to the perceived consequences of the decision: patients may not feel a strong need to act in accordance with the lifestyle decision made, but still prefer to determine themselves what to do or not. However, given the increasing awareness of the crucial role of selfmanagement for beneficial outcomes of chronic care [32], it is essential to actively involve patients with long-term conditions in decision-making about their lifestyle.

Congruent to Makoul and Clayman [4], our study shows that patient preferences are an essential element of the SDM concept. We found a significant, but moderate correlation between patients' preferences regarding decision-making and their actual involvement in the decision-making process. In medical care and home care, patients usually feel that their involvement in decision-making is in accordance with their preferences, which is in line with findings of other studies [2], [9] and [10]. Regarding occupational healthcare issues, a discrepancy exists: patients attach considerable importance to being involved in decision-making, but do not experience much involvement. Occupational physicians might have difficulty allowing clients to have more influence on decisions because of possibly conflicting goals: caring for their clients who are on sick-leave on the one hand, and working towards a prompt return to work because of their obligations to their employers on the other [33]. Notwithstanding this, involving patients in the decision-making process may be advantageous for both goals, because patients themselves can best evaluate which interventions will fit in with their needs. This will increase the likelihood and motivation of patients to return to work.

The finding that older patients attach equal or even more importance to SDM than younger patients is in line with an earlier study on general practice patients [2]. However, contrary to other findings [2], [9], [20] and [25], our results show that older patients also experience more involvement in decision-making than younger ones. This may be explained by younger patients making higher demands with regard to SDM, which may lead to a perception of lower involvement. Another possible explanation is that older patients with long-term conditions may feel more at ease in contacts with their care providers, due to the generally long-lasting nature of the relationship and the expertise they have obtained throughout the years. This may be different for (acute) patients of general practices.

\subsubsection{Limitations of the study}

Besides its strengths (attention to issues other than medical care, focus on context in addition to individual characteristics), this study also has some weaknesses. First, it was not possible to use a validated self-report instrument to assess the importance attached to SDM for the purpose of our study. We therefore formulated a question based on the importance attached to several aspects of communication as assessed by the QuoteComm [2], [9] and [10]. Our question was simple and, as reflected by the low number of missing values, seems to have been well understood by the patients. Nevertheless, it would be worthwhile developing a theory-based, multi-item questionnaire assessing both preferences and experiences regarding SDM. The Makoul and Clayman model [4] could serve as a theoretical basis for such an instrument.

Another limitation concerns the number of patients who responded to our questions about SDM. A substantial number answered the questions on SDM regarding medical care and lifestyle issues, but far fewer answered these questions regarding home care and occupational healthcare issues. This is because many respondents did not receive home care or occupational healthcare, and of those who did, not all experienced a decision-making situation during the last year. It would be interesting to study SDM in larger samples of people receiving home care or occupational healthcare.

\subsubsection{Theoretical considerations}

Theoretical models of SDM and related concepts identify factors that contribute to the explanation of differences in decision-making processes and outcomes in medical care. Explanatory factors that are usually distinguished are individual characteristics of patients and medical care providers (i.e. sociodemographics, preferences and competencies) and their (different) perceptions of the treatment options (for instance, perceived risks and benefits, uncertainty of outcome). Several studies have addressed the question whether patients really want to be involved in decision-making processes [23], [24] and [34]. The empirical evidence found has been mixed and conceptual ambiguity has been mentioned as a cause of these inconsistent results [35]. Although we believe that this explanation is valid, we would like to suggest an 
Brink-Muinen, A. van den, Spreeuwenberg, P., Rijken, M. Preferences and experiences of chronically ill and disabled patients regarding shared decision-making: does the type of care to be decided upon matter? Patient Education and Counseling: 2011, 84(1), 111-117

additional explanation based on our current research. It seems to us that whether a patient wants to be involved in decision-making has been treated in most other research as some kind of trait characteristic of patients or at least determined by rather stable patient characteristics such as education, locus of control or self-efficacy. Few authors have suggested that patients' preferences and experiences may develop over time as people are more exposed or familiar with involvement in decision-making [36] or vary from one situation or context to another for an individual patient [35]. Our study provides evidence for the latter. We believe that future research on patients' preferences and experiences regarding SDM should pay more attention to individual changes over time and variation across different care situations.

\subsection{Conclusion}

The general conclusion is that the type of care to decide upon impacts on the importance patients attach to SDM as well as on their actual involvement in decision-making. Moreover, the value of the current study is that it shows how the context (here: the type of care to be decided upon) impacts on patients' preferences and experiences regarding SDM, in addition to individual patient and provider characteristics.

\subsection{Practice implications}

In view of the recent developments in chronic care, where patient's self-management and responsibility have acquired considerable importance, it is necessary that care providers pay close attention to their patients' preferences (and competencies) with regard to their role in decision-making. Care providers need to be aware of the fact that patients' preferences regarding SDM may differ according to the type of care issue at stake. We therefore suggest that care providers assess their patients' preferred level of involvement each time a new decision has to be made. A screening tool that can easily be used by clinicians might help to clarify patients' needs and preferences regarding decision-making, but awareness may be more essential than technical aids. Continuing attention to the preferred patient role may help to reduce the gap between patients' preferences and experiences.

Furthermore, our study suggests that especially occupational healthcare providers should put more effort into involving their clients in decision-making. It is important that all care providers, including occupational healthcare professionals, try to involve patients in decision-making to the extent they desire. This may be difficult and may need training and experience to develop the necessary skills. Unfortunately, very little is known about the barriers and facilitators to implement SDM as perceived by other healthcare providers (than medical practitioners) [37]. For this reason, Gravel and colleagues suggest that future research on the implementation of SDM in clinical practice should target a more diverse group of healthcare professionals. Whatever the perceived limitations may be, a positive attitude towards SDM of healthcare providers is essential as well as optimistic, but realistic expectations regarding patient involvement in decision-making.

\section{CONFLICT OF INTEREST}

The authors do not have any actual or potential conflicts of interest that could inappropriately influence (bias) our work.

\section{ACKNOWLEDGEMENTS}

Role of funding: This study was performed within the research programme 'National Panel of people with Chronic illness or Disability' (NPCD), financed by the Ministry of Health, Welfare and Sport and the Ministry of Social Affairs and Employment of The Netherlands. We thank all patients for their participation in the study.

\section{REFERENCES}

[1] J.M. Bensing and W. Langewitz, Die Artzliche Konsultation, The medical consultation. In: Uxcull, Editor, Psychosomatische Medizin (2002), pp. 415-424.

[2] A. van den Brink-Muinen, A.M. van Dulmen, H.C.J.M. de Haes, A.Ph. Visser, F.G. Schellevis and J.M. Bensing, Has patients' involvement in the decision-making process in general practice changed over time?, Health Expect 9 (2006), pp. 333-342.

[3] H. de Haes, Dilemmas in patient centeredness and shared decision making: a case for vulnerability, Patient Educ Couns 62 (2006), pp. 291-298. 
Brink-Muinen, A. van den, Spreeuwenberg, P., Rijken, M. Preferences and experiences of chronically ill and disabled patients regarding shared decision-making: does the type of care to be decided upon matter? Patient Education and Counseling: 2011, 84(1), 111-117

[4] G. Makoul and M.L. Clayman, An integrative model of shared decision making in medical encounters, Patient Educ Couns 60 (2006), pp. 301-312.

[5] C. Charles, A. Gafni and T. Whelan, Decision-making in the physician-patient encounter: revisiting the shared treatment decision-making model, Soc Sci Med 49 (1999), pp. 651-661.

[6] G. Elwyn, A. Edwards, S. Mowle, M. Wensing, C. Wilkinson and P. Kinnersley et al., Measuring the involvement of patients in shared decision-making: a systematic review of literature, Patient Educ Couns 43 (2001), pp. 5-22.

[7] N. Mead, P. Bower and M. Hann, The impact of general practitioners' patient-centredness on patients' post-consultation satisfaction and enablement, Soc Sci Med 55 (2002), pp. 283-299.

[8] A. Edwards and G. Elwyn, Inside the black box of shared decision-making. Distinguishing between the process of involvement and who makes the decision, Health Expect 9 (2006), pp. 248-258.

[9] van den Brink-Muinen A, van Dulmen AM, Schellevis FG, Bensing JM (red.). Oog voor communicatie: huisarts-patiënt communicatie in Nederland. Tweede Nationale Studie naar ziekten en verrichtingen in de huisartspraktijk [Focus on communication: doctor-patient communication in the Netherlands. Second Dutch National Survey of General Practice]. Utrecht: NIVEL; 2004.

[10] A. van den Brink-Muinen, A.M. van Dulmen, H.P. Jung and J.M. Bensing, Do our talks with patients meet their expectations?, J Fam Practice 7 (2007), pp. 559-568.

[11] A.M. van Dulmen and J.M. Bensing, The effect of context in healthcare. A programming study, NIVEL, Utrecht, The Netherlands (2001).

[12] T.F. Hack, L.F. Degner, P. Watson and L. Sinha, Do patients benefit from participating in medical decision making? Longitudinal follow-up of women with breast cancer, Psychooncology 15 (2006), pp. 919.

[13] T.J. Brady, The patient's role in rheumatology care, Curr Opin Rheumatol 10 (1998), pp. $146-151$.

[14] C. Stubblefield and S. Mutha, Provider-patient roles in chronic disease management, Allied Health 31 (2002), pp. 87-92.

[15] P. Rosen, A. Anell and C. Hiortsberg, Patient views on choice and participation in primary health care, Health Policy 55 (2001), pp. 121-128.

[16] G. Elwyn and A. Edwards, Shared decision-making and the concept of equipoise: the competences of involving patients in healthcare choices, Brit J Gen Pract 50 (2000), pp. 892-897.

[17] H. Ishikawa, H. Hashimoto and E. Yano, Patients' preferences for decision making and the feeling of being understood in the medical encounter among patients with rheumatoid arthritis, Arthritis Rheum 55 (2006), pp. 878-883.

[18] N. Richards and A. Coulter, Is the NHS becoming more patient-centred?, Picker Institute Europe (2007).

[19] W. Corser, M. Holmes-Rovner, C. Lein and V. Gossain, A shared decision-making primary care intervention for type 2 diabetes, Diabetes Educator 33 (2007), pp. 700-708.

[20] A. Robinson and R. Thomson, Variability in patient preferences for participating in medical decisionmaking: implication for the use of decisions support tools, Qual Health Care 10 (Suppl. 1) (2001), pp. i34i38.

[21] V.M. Montori, A. Gafni and C. Charles, A shared treatment decision-making approach between patients with chronic conditions and their clinicians: the case of diabetes, Health Expect 9 (2006), pp. 25-36.

[22] C. Heesen, S. Köpke, T. Richter and J. Kasper, Shared decision making and self-management in multiple sclerosis-a consequence of evidence, J Neurol 254 (Suppl. 2) (2007), pp. II/116-II/121.

[23] B.R. Cassileth, R.V. Zupkis, K. Sutton-Smith and V. March, Information and participation among cancer patients, Ann Intern Med 92 (1980), pp. 832-836.

[24] J. Ende, L. Kazis, A. Ash and M.A. Moskowitz, Measuring patients' desire for autonomy: decisionmaking and information-seeking preferences among medical patients, J Gen Intern Med 4 (1989), pp. 2330.

[25] H. Haes de and N. Koedoot, Patient-centered decision-making in palliative cancer treatment: a world of paradoxes, Patient Educ Couns 50 (2003), pp. 43-49.

[26] F. Légaré, A.M. O'Connor, I.D. Graham, G.A. Wells and S. Tremblay, Impact of the Ottawa Decision Support Framework on the agreement and the difference between patients' and physicians' decisional conflict, Med Decis Making 26 (2006), pp. 373-390.

[27] M. Rijken, M. van Kerkhof, J. Dekker and F.G. Schellevis, Comorbidity of chronic diseases. Effects of disease pairs on physical and mental functioning, Qual Life Res 14 (2005), pp. 45-55. 
Brink-Muinen, A. van den, Spreeuwenberg, P., Rijken, M. Preferences and experiences of chronically ill and disabled patients regarding shared decision-making: does the type of care to be decided upon matter? Patient Education and Counseling: 2011, 84(1), 111-117

[28] J.S.J. de Wit, De SCP-maat voor beperkingen. Een technische toelichting, SCP measures about disabilities. A technical explanation, The Netherlands Institute for Social Research/SCP, Rijswijk (1997) [SCP-werkdocument 40].

[29] J.E. Ware and C.D. Sherbourne, The MOS 36-item Short Form Health Survey (SF-36): I. Conceptual framework and item selection, Med Care 30 (1992), pp. 473-483.

[30] K.I. Van der Zee, R. Sanderman, J.W. Heyink and H. de Haes, Psychometric qualities of the RAND 36Item Health Survey 1.0: a multidimensional measure of general health status, Int J Behav Med 3 (1996), pp. 104-122.

[31] A.H. Leyland and P.P. Groenewegen, Multilevel modelling and public health policy, Scand J Public Health 31 (2003), pp. 267-274.

[32] M. Rijken, M. Jones, M. Heijmans and A. Dixon, Supporting self-management. In: E. Nolte and M. McKee, Editors, Caring for people with chronic conditions. A health system perspective. European Observatory on Health Systems and Policies Series, Open University Press, Berkshire, UK (2008), p. 2008.

[33] A. van den Brink-Muinen, Hoe communiceren bedrijfsartsen en verzekeringsartsen met chronisch zieken en gehandicapten?, How do occupational and insurance physicians communicate with the patients?, TBV 9 (2008), pp. 375-380.

[34] A. Edwards and G. Elwyn, Shared decision-making in health care: achieving evidence-based patient choice. In: A. Edwards and G. Elwyn, Editors, Shared decision-making in health care. Achieving evidence-based patient choice (2nd ed.), Oxford University Press, UK, Oxford (2009).

[35] D.L. Frosch and R.M. Kaplan, Shared decision making in clinical medicine: past research and future directions, Am J Prev Med 17 (1999), pp. 285-294.

[36] M. Longo, D. Cohen, K. Hood, A. Edwards, M. Robling and G. Elwyn et al., Involving patients in primary care consultations: assessing preferences using discrete choice experiments, Brit J Gen Pract 56 (2006), pp. 35-42.

[37] K. Gravel, F. Légaré and I.D. Graham, Barriers and facilitators to implementing shared decision-making in clinical practice: a systematic review of health professionals perceptions, Implement Sci 1 (2006), pp. $1-16$.

\section{[TABLES AND BOXES]}

Box 1. Categorization of care issues according to type and caregivers involved

\begin{tabular}{llll}
\hline Medical care & Home care & Occupational healthcare & Lifestyle \\
\hline $\begin{array}{l}\text { Type of care issue } \\
\text { Medical treatment }\end{array}$ & Nursing & Restarting work & Food and diet \\
$\begin{array}{l}\text { Medication } \\
\text { Referral }\end{array}$ & Personal care & Adaptation of workload & Smoking \\
Examination, tests, diagnostics & Domestic care & Adapted furniture & Alcohol use \\
Activating and & Adapted equipment & Physical exercise \\
Other & facilitating support & Other & Other \\
$\begin{array}{l}\text { Caregiver involved } \\
\text { General practitioner }\end{array}$ & Other & Occupational physician & General practitioner \\
$\begin{array}{l}\text { Medical specialist } \\
\text { Allied health care professional, e.g. physiotherapist }\end{array}$ & Home help & Occupational therapist & Medical specialist \\
& General practitioner & Occupational nurse & Allied healthcare professional, \\
& & Occupational phychologist & Dietician \\
\hline
\end{tabular}


Brink-Muinen, A. van den, Spreeuwenberg, P., Rijken, M. Preferences and experiences of chronically ill and disabled patients regarding shared decision-making: does the type of care to be decided upon matter? Patient Education and Counseling: 2011, 84(1), 111-117

Table 1

Characteristics of the patient samples, by type of care in decision-making.

\begin{tabular}{|c|c|c|c|c|}
\hline & $\begin{array}{l}\text { Medical care } \\
(N=577)\end{array}$ & $\begin{array}{l}\text { Home care } \\
(N=189)\end{array}$ & $\begin{array}{l}\text { Occupational healthcare } \\
(N=61,<65 \text { years })\end{array}$ & $\begin{array}{l}\text { Lifestyle issues } \\
(N=312)\end{array}$ \\
\hline Female patients (\%) & 68 & 80 & 69 & 63 \\
\hline Age in years (mean, std. dev.) & $60(15)$ & $67(13)$ & $47(9)$ & $59(13)$ \\
\hline \multicolumn{5}{|l|}{ Educational level (\%) } \\
\hline Low & 37 & 49 & 22 & 39 \\
\hline Moderate & 44 & 38 & 51 & 42 \\
\hline High & 19 & 13 & 27 & 19 \\
\hline \multicolumn{5}{|l|}{ Index disease ${ }^{\mathrm{a}}(\%)$} \\
\hline Cardiovascular & 12 & 15 & 7 & 9 \\
\hline Asthma/COPD & 15 & 9 & 16 & 14 \\
\hline Musculoskeletal & 19 & 22 & 15 & 18 \\
\hline Cancer & 3 & 3 & 2 & 2 \\
\hline Diabetes & 10 & 9 & 5 & 12 \\
\hline Neurological & 5 & 8 & 7 & 5 \\
\hline Digestive & 3 & 2 & 10 & 2 \\
\hline Other & 12 & 5 & 15 & 13 \\
\hline No chronic disease/unknown ${ }^{\mathrm{b}}$ & 22 & 28 & 25 & 25 \\
\hline Multi-morbidity (\%) & 52 & 66 & 30 & 49 \\
\hline \multicolumn{5}{|l|}{ Life threateningness of condition (\%) } \\
\hline To a less extent & 79 & 77 & 85 & 82 \\
\hline Average & 16 & 17 & 13 & 15 \\
\hline To a large extent & 5 & 1 & 2 & 3 \\
\hline \multicolumn{5}{|l|}{ Progressiveness of condition (\%) } \\
\hline To a less extent & 47 & 33 & 47 & 41 \\
\hline Average & 37 & 47 & 49 & 43 \\
\hline To a large extent & 16 & 20 & 4 & 16 \\
\hline \multicolumn{5}{|l|}{ Severity of physical disability (\%) } \\
\hline No/mild & 32 & 10 & 49 & 29 \\
\hline Moderate & 42 & 43 & 41 & 47 \\
\hline Severe & 26 & 47 & 10 & 24 \\
\hline \multicolumn{5}{|l|}{ Self-rated health (\%) } \\
\hline Excellent & 1 & 0 & 2 & 1 \\
\hline Very good & 4 & 1 & 7 & 2 \\
\hline Good & 33 & 18 & 48 & 32 \\
\hline Fair & 54 & 65 & 40 & 54 \\
\hline Poor & 8 & 16 & 3 & 11 \\
\hline
\end{tabular}

a The index disease is the (oldest) chronic disease diagnosed by a medical practitioner

b This category refers to cases included on the basis of a moderate to severe physical disability, not being diagnosed with a chronic disease or presence of a chronic disease unknown. 
Brink-Muinen, A. van den, Spreeuwenberg, P., Rijken, M. Preferences and experiences of chronically ill and disabled patients regarding shared decision-making: does the type of care to be decided upon matter? Patient Education and Counseling: 2011, 84(1), 111-117

Table 2

Results of multilevel linear regression analyses with importance attached to SDM and actual involvement in decision-making being the dependent variables.

\begin{tabular}{|c|c|c|c|c|c|c|}
\hline \multirow[t]{2}{*}{ Fixed part } & \multicolumn{2}{|c|}{ Importance } & \multicolumn{3}{|c|}{ Involvement } & \multirow[t]{2}{*}{$\chi^{2}$} \\
\hline & $\beta$ & Standard error & $\beta$ & \multicolumn{2}{|r|}{ Standard error } & \\
\hline \multicolumn{7}{|l|}{ Care setting ${ }^{a}$} \\
\hline Intercept & 0.00 & 0.04 & 0.00 & & 0.04 & \\
\hline Home care & -0.01 & 0.12 & -0.10 & & 0.12 & $0.33 \ldots$ \\
\hline Occupational healthcare & $0.36^{*}$ & 0.18 & $-0.54 *$ & & 0.13 & $17.09^{\cdots}$ \\
\hline Lifestyle issues & $-0.38^{\cdots}$ & 0.09 & $-0.19^{\circ}$ & & 0.08 & 2.80 \\
\hline \multicolumn{7}{|l|}{ Patient characteristics } \\
\hline Gender ( $0=$ male, 1 =female $)$ & 0.06 & 0.09 & $-0.25^{*}$ & & 0.09 & $6.94^{*}$ \\
\hline Age (years) & $0.01^{*}$ & $0.00^{\circ}$ & $0.01^{*}$ & & 0.00 & 0.02 \\
\hline Education level (scale 1-7) & -0.04 & 0.02 & -0.04 & & 0.02 & 0.00 \\
\hline Caregiver's gender ( $0=$ male, $1=$ female $)$ & - & - & -0.02 & & 0.08 & - \\
\hline \multicolumn{7}{|l|}{ Severity of health condition } \\
\hline Life threateningness (scale $1-3$ ) & 0.07 & 0.09 & -0.01 & & 0.09 & 0.52 \\
\hline Progressiveness (scale 1-3) & -0.02 & 0.06 & 0.07 & & 0.06 & 1.06 \\
\hline Multi-morbidity ( 1 =yes) & 0.11 & 0.08 & 0.06 & & 0.09 & 0.21 \\
\hline Self-rated health (scale 1-5) & 0.09 & 0.06 & -0.09 & & 0.07 & $4.64^{\circ}$ \\
\hline \multicolumn{7}{|l|}{ Severity of physical disability ${ }^{b}$} \\
\hline Moderate & 0.02 & 0.10 & -0.16 & & 0.10 & 1.96 \\
\hline Severe & 0.07 & 0.12 & -0.13 & & 0.13 & 1.41 \\
\hline \multirow[t]{2}{*}{ Random part } & \multicolumn{2}{|l|}{ Importance } & & \multicolumn{3}{|c|}{ Involvement } \\
\hline & Estimate & Standard error & & \multicolumn{2}{|l|}{ Estimate } & Standard error \\
\hline \multicolumn{7}{|l|}{ Care setting } \\
\hline Medical care & 0.80 & 0.09 & \multicolumn{3}{|c|}{0.74} & 0.09 \\
\hline Home care & 0.85 & 0.16 & \multicolumn{3}{|c|}{0.46} & 0.11 \\
\hline Occupational healthcare & 1.11 & 0.27 & \multicolumn{3}{|c|}{0.36} & 0.13 \\
\hline Lifestyle & 0.75 & 0.11 & & 0.48 & & 0.09 \\
\hline Patient level & 0.12 & 0.07 & & 0.33 & & 0.07 \\
\hline & Importance & & & Inve & lvement & \\
\hline & Estimate & & & Star & idard error & \\
\hline Covariance & & & & & & \\
\hline Correlation & & & 0.45 & & & \\
\hline General practice level & 0.000 & 0.000 & & 0.00 & & 0.000 \\
\hline
\end{tabular}

a Reference group: medical care

Reference group: no/mild disability.

$P<.05$.

$P<.01$.

$\cdots P<.001$. 